\title{
Migration of mouse-induced pluripotent stem cells to glioma-conditioned medium is mediated by tumor-associated specific growth factors
}

\author{
SHINICHIRO KOIZUMI ${ }^{1}$, CHUNYU GU ${ }^{1}$, SHINJI AMANO ${ }^{1}$, SEIJI YAMAMOTO ${ }^{3}$, \\ HAYATO IHARA $^{2}$, TSUTOMU TOKUYAMA ${ }^{1}$ and HIROKI NAMBA ${ }^{1}$ \\ Departments of ${ }^{1}$ Neurosurgery, and ${ }^{2}$ Physiology; ${ }^{3}$ Photon Medical Research Center, \\ Hamamatsu University School of Medicine, Hamamatsu 431-3192, Japan
}

Received October 5, 2010; Accepted December 29, 2010

DOI: $10.3892 / \mathrm{ol} .2011 .234$

\begin{abstract}
Neural and mesenchymal stem cells have extensive tropism for malignant glioma. The tumor tropism of induced pluripotent stem (iPS) cells was tested using the Matrigel invasion assay. Mouse iPS cells showed a significant tropism to the conditioned media prepared from six rodent and human glioma cell lines and this tropism to the glioma conditioned media was partially blocked by the neutralizing antibodies for four major tumor-associated growth factors [stem cell factor (SCF), platelet-derived growth factor $\mathrm{BB}$ (PDGF-BB), stromal-derived factor- $1 \alpha$ (SDF-1 $\alpha)$ and vascular endothelial growth factor (VEGF)], which are secreted from the malignant gliomas. The tropism of the iPS cells was enhanced by the growth factors in a concentration-dependent manner from 0.1 to $100 \mathrm{ng} / \mathrm{ml}$. The receptors for those growth factors (c-Kit, ICAM-1, CXCR4 and VEGFR2), measured by reverse transcriptase-polymerase chain reaction, were highly up-regulated in the mouse iPS cells compared to the mouse fibroblasts. The results showed that the specific growth factors secreted from the gliomas strongly attracted the iPS cells. Therefore, gene therapies using iPS cells as vectors to deliver anti-tumor agents are novel strategies for the treatment of malignant gliomas that deeply infiltrate the brain.
\end{abstract}

\section{Introduction}

Malignant glioma is the most common subtype of primary brain tumors. Glioblastoma multiforme, the most malignant glioma subtype, is associated with a median survival duration in the range of $6-18$ months $(1,2)$. Due to their

Correspondence to: Dr Hiroki Namba, Department of Neurosurgery, Hamamatsu University School of Medicine, 1-20-1 Handayama, Higashi-ku, Hamamatsu 431-3192, Japan

E-mail: hnamba@hama-med.ac.jp

Key words: induced pluripotent stem cells, glioma, migration, growth factors specific properties, including infiltrative growth and resistance to tumoricidal agents, numerous advances in conventional therapeutic approaches, such as extensive surgical excision and adjuvant radio- and chemotherapy have been unsuccessful $(3,4)$. This poor outcome relates, at least in part, to the inability to deliver therapeutic agents to the tumor (5). Accumulating evidences of tropism of stem cells for malignant glioma (6) show that gene therapies, using stem cells as the vehicles for therapeutic agents, have emerged as a promising treatment modality for malignant glioma. Furthermore, a number of preclinical trials of stem cell-based gene therapies have shown that neural stem cells (NSCs) are effective tumor-specific delivery vehicles for transgenes to malignant glioma (7-12). Similarly, evidence indicated that bone marrow-derived mesenchymal stem cells (MSCs) are effective vehicles for the delivery of gene therapies to malignant glioma $(5,13)$. In previous studies, the extensive tropism of NSC and MSC for malignant glioma was observed, as well as a sufficient effect of the gene therapy using a suicide gene, the herpes simplex virus-thymidine kinase (HSVtk) gene, and a prodrug, ganciclovir (GCV) (14-18).

The mechanism underlying the tropism of NSC and MSC for tumors in general, and malignant gliomas in particular, has recently been identified as including soluble factors, cell adhesion molecules and extracellular matrix components (19-22). Malignant gliomas produce growth factors, cytokines and chemokines, which then mediate the tropism of NSC and MSC for malignant glioma. Previous studies using in vitro migration assays suggested that the exposure of NSC and MSC to specific growth factors, particularly stem cell factor (SCF) (21), platelet-derived growth factor BB (PDGF-BB) (22), stromal-derived factor-1 $\alpha(\mathrm{SDF}-1 \alpha)(19)$ and vascular endothelial growth factor (VEGF) (20), enhanced the migration of NSC and MSC (19-22).

Induced pluripotent stem (iPS) cells have been established both in rodents and humans, and various pre-clinical studies have been performed in the field of regeneration therapy (23). As previously noted, NSCs and MSCs are excellent vehicles for gene delivery to gliomas. Thus, the use of iPS cells from patients is likely to be more ideal in terms of the quality control of the cells and the invasiveness of cell collection. In the present study, the tumor-tropic activity of iPS cells was 
examined to evaluate whether the cells could be utilized as vehicles for glioma gene therapies.

\section{Materials and methods}

Cell culture. The mouse iPS cells, iPS-MEF-Ng-20D-17 established by Yamanaka et al (23), were obtained from Riken Biosource Center (Tsukuba, Japan) and were cultured on mitotically inactivated mouse embryonic fibroblasts in the medium composed of Dulbecco's modified Eagle's medium (DMEM) high glucose 1X (Invitrogen, Tokyo, Japan) supplemented with $15 \%$ fetal bovine serum (FBS; Sigma-Aldrich Japan, Tokyo, Japan), 0.1 mM MEM non-essential amino acids (Invitrogen), $0.1 \mathrm{mM}$ 2-mercaptoethanol (Sigma-Aldrich Japan) and 1,000 U/ml leukemia inhibitory factor (ESGRO; Millipore, Temecula, CA, USA) on a gelatin-coated dish at $37^{\circ} \mathrm{C}$ in a $5 \% \mathrm{CO}_{2}$ humidified atmosphere according to the protocol previously reported (24). Experiments were performed using the mouse iPS cells during passages 2-4. The mouse glioma cell line GL261 and the rat glioma cell line C6 were purchased from Health Science Research Resources Bank (Osaka, Japan), and the human glioma cell lines A172, T98G, YKG1 and U87 from the American Type Culture Collection (ATCC, Manassas, VA, USA). The cells were grown in DMEM (Sigma-Aldrich, Japan) supplemented with $10 \%$ FBS, penicillin $(100 \mathrm{IU} / \mathrm{ml})$ and streptomycin $(100 \mu \mathrm{g} / \mathrm{ml})$ at $37^{\circ} \mathrm{C}$ in a humidified atmosphere of $5 \% \mathrm{CO}_{2}$. The mouse iPS cells were dissociated at $37^{\circ} \mathrm{C}$ for 2 min using $0.25 \%$ trypsin with $1 \mathrm{mM}$ EDTA, and the glioma cell lines were dissociated using $0.25 \%$ trypsin with $1 \mathrm{mM}$ EDTA for $3 \mathrm{~min}$.

Migration of induced pluripotent stem cells towards the glioma-conditioned media and specific growth factors. The in vitro migratory capacity of iPS cells was assessed using the 24-well Matrigel Invasion Chamber (BD Biosciences Discovery Labware, Bedford, MA, USA), which contained an $8-\mu \mathrm{m}$ pore size PET membrane treated with Matrigel Basement Membrane Matrix in the insert (25). First, $0.5 \mathrm{ml}$ DMEM was added to the interior of the inserts and the bottom of the wells and allowed to rehydrate for $2 \mathrm{~h}$ at $37^{\circ} \mathrm{C}$ in a $5 \% \mathrm{CO}_{2}$ humidified atmosphere. The DMEM was then carefully removed without disturbing the layer of Matrigel Matrix on the membrane. The mouse iPS cells were washed twice in phosphate-buffered saline (PBS) and resuspended to $1 \times 10^{5}$ cells $/ \mathrm{ml}$. Cell suspension $(0.5 \mathrm{ml})\left(5 \times 10^{4}\right.$ cells $)$ was added to the upper insert. The lower chamber was filled with $0.75 \mathrm{ml}$ of conditioned medium (CM) of the glioma cell lines as well as unconditioned medium (DMEM) as a control. CM was obtained by collecting, centrifuging and filtering medium from GL261, C6, A172, T98G, YKG1 and U87 clones (1x106), which were cultured in $10 \mathrm{ml}$ of DMEM without FBS for $48 \mathrm{~h}$. For the migration stimulation assays, the specific growth factors SCF, PDGF-BB, SDF-1 $\alpha$ and VEGF were added to the lower chamber at concentrations from 0.1 to $100 \mathrm{ng} / \mathrm{ml}$. For the specific growth factors blocking experiments, CM from the GL261 mouse glioma cell line was incubated with anti-SCF, anti-PDGF-BB, anti-SDF-1 $\alpha$ and anti-VEGF neutralizing antibodies (Abcam PLC, Tokyo, Japan) for $3 \mathrm{~h}$ prior to transfer into the lower chamber at concentrations of 1 and $10 \mu \mathrm{g} / \mathrm{ml}$.
Following incubation of the Matrigel Invasion Chambers for $24 \mathrm{~h}$ at $37^{\circ} \mathrm{C}$ in a $5 \% \mathrm{CO}_{2}$ humidified atmosphere, the noninvading cells and/or Matrigel Matrix were removed from the upper surface of the membrane in the inserts with a cotton swab. The cells migrating to the lower surface of the membrane were stained with the Diff-Quick kit (International Reagents, Hyogo, Japan), which was achieved by sequentially transferring the inserts to air dry. The nuclei of the migrated cells were counted in 4 high-power fields (HPF) per membrane using a magnification of $\times 200$. All experiments were conducted in triplicate and results were expressed as the mean number of cells migrating per field \pm SD.

Expression of the receptors for growth factors. The status of the growth factor receptors of mouse iPS cells was analyzed by reverse transcriptase-polymerase chain reaction (RT-PCR). The receptors used for the growth factors SCF, PDGF-BB, SDF-1 $\alpha$ and VEGF were c-Kit, intercellular adhesion molecule-1 (ICAM-1), CXC chemokine receptor 4 (CXCR4) and vascular endotherial growth factor receptor 2 (VEGFR2), respectively. Total RNA was extracted from the mouse iPS cells and from the control mouse fibroblasts using TRIzol reagent (Invitrogen) according to the manufacturer's instructions. cDNA was generated from $1 \mu \mathrm{g}$ of total RNA from each sample. The primers used were: c-Kit, forward, 5'-CAGAGGCTTAGCGGAGTGAAGTG-3' and reverse, 5'-TCCCTGGATTGGCAGCATTAC-3'; ICAM-1, forward, 5'-AACTGTGGCACCGTGCAGTC-3' and reverse, 5'-AGGG TGAGGTCCTTGCCTACTTG-3'; CXCR4, forward, 5'-CCG GTACCTCGCTATTGTCCAC-3' and reverse, 5'-GGATCCAG ACGCCCACACATAGA-3'; VEGFR2, forward, 5'-TCTCC GTTATTGCTTCTGTTAG-3' and reverse, 5'-GTGATACC TTGCACAGAGTGACAC-3'; $\beta$-actin, forward, 5'-TCAGGT CATCACTATCGGCAAT-3' and reverse,5'-AAAGAAAGGGT GTAAAACGCA-3'. The PCR conditions consisted of an initial denaturation at $94^{\circ} \mathrm{C}$ for 2 min followed by 30 cycles of denaturation at $94^{\circ} \mathrm{C}$ for $30 \mathrm{sec}$, annealing at $50^{\circ} \mathrm{C}$ for $30 \mathrm{sec}$ and extension at $72^{\circ} \mathrm{C}$ for $30 \mathrm{sec}$ in a thermal cycler (LightCycler, Roche Diagnostics K.K., Tokyo, Japan). The integrated density values were determined by extrapolation using the cRNA standard curve, and normalized with that of $\beta$-actin. The fold increase was calculated from the results of three independent experiments.

Statistical analysis. The data (mean $\pm \mathrm{SD}$ ) were analyzed using the two-tailed unpaired Student's t-test with 95\% confidence interval for a two-group comparison. Differences were considered significant at $\mathrm{p}<0.01$.

\section{Results}

Migration of induced pluripotent stem cells towards the glioma-conditioned media and specific growth factors. Directional migration of mouse iPS cells towards the CM prepared from six different glioma cell lines (GL261, C6, A172, T98G, YKG1 and U87) was analyzed using the 24-well Matrigel Invasion Chamber. A high number of mouse iPS cells were observed migrating towards the CM of GL261, C6, A172, T98G, YKG1 and U87 $(388 \pm 70,407 \pm 40,355 \pm 59$, $401 \pm 14,403 \pm 58$ and $375 \pm 46$ per $4 \mathrm{HPF}$, respectively), whereas 
A

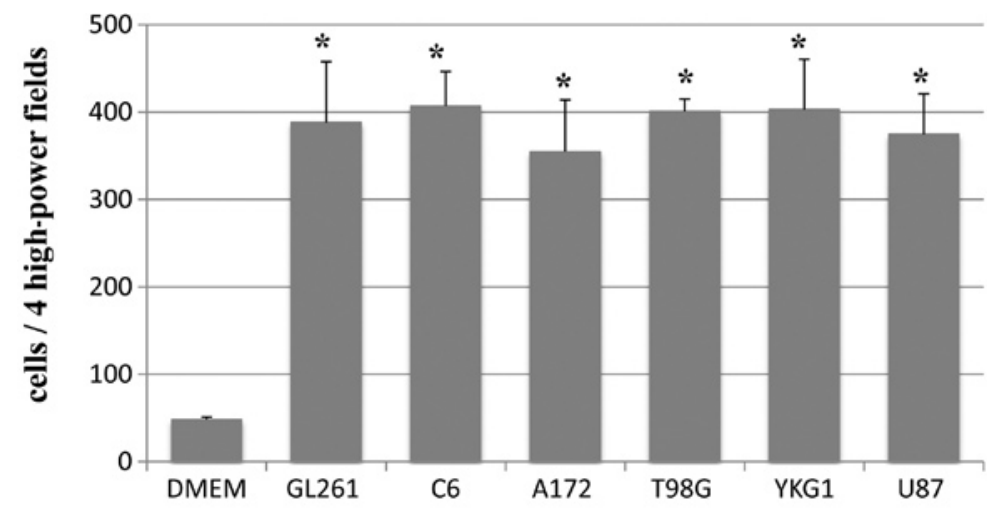

B

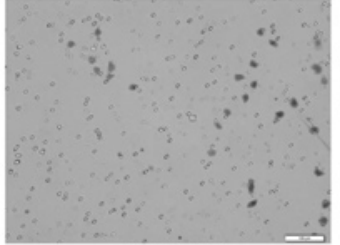

DMEM

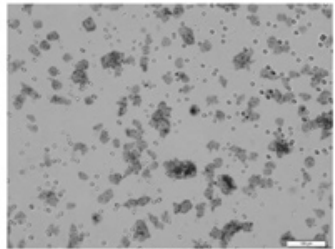

GL261

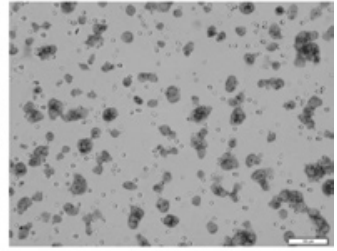

T98G

Figure 1. (A) Migration of the mouse iPS cells induced by conditioned media (CM) prepared from six rodent (GL261 and C6) and human (A172, T98G, YKG1 and U87) glioma cell lines and unconditioned medium Dulbecco's modified Eagle's medium (DMEM) in the 24-well Matrigel Invasion Chamber. The migration was significantly increased by the glioma $\mathrm{CM}$ (triplicate, means $\pm \mathrm{SD},{ }^{*} \mathrm{p}<0.001$ ). (B) Representative photomicrographs of the micropore membranes from DMEM, GL261-CM and T98G-CM (bars, $100 \mu \mathrm{m})$.

A

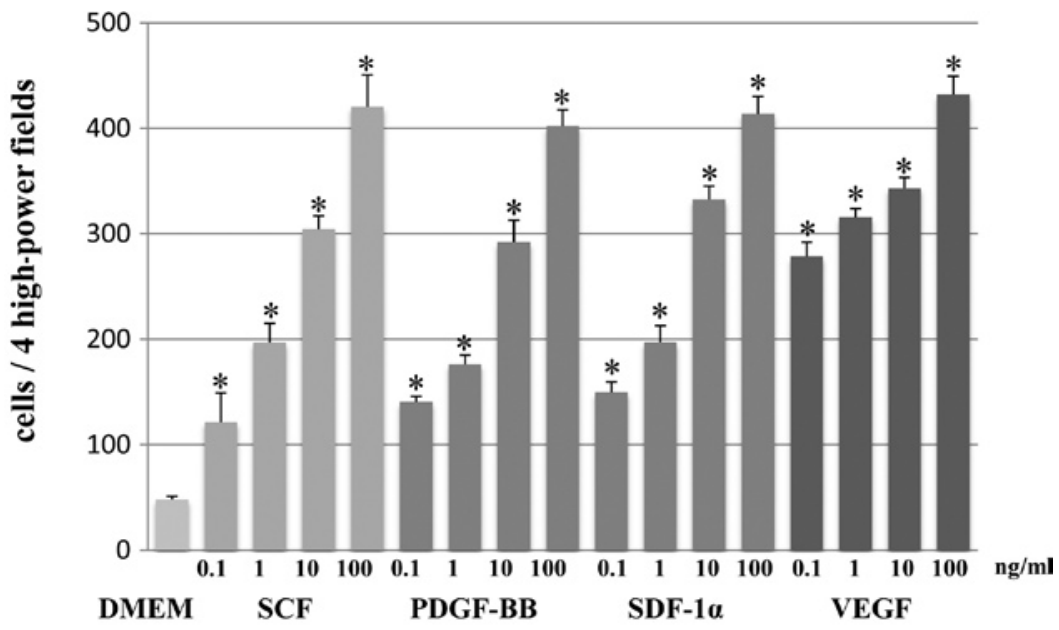

B

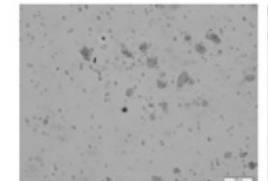

SDF-1 20.1

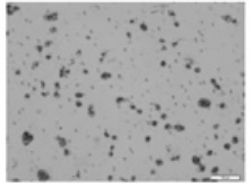

1

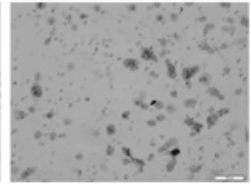

10

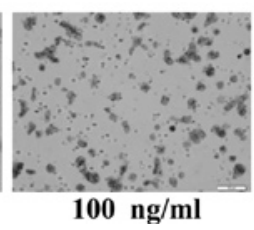

Figure 2. (A) Chemotactic migration of the mouse iPS cells by increasing concentrations of specific growth factors [stem cell factor, platelet-derived growth factor BB, stromal-derived factor-1 $\alpha$ (SDF-1 $\alpha$ ) and vascular endothelial growth factor] in the 24-well Matrigel Invasion Chamber. The migration significantly increased with the stimulation of each growth factor in a concentration-dependent manner at concentrations of $0.1,1,10 \mathrm{and} 100 \mathrm{ng} / \mathrm{ml}$ compared to Dulbecco's modified Eagle's medium (triplicate, means $\pm \mathrm{SD},{ }^{*} \mathrm{p}<0.001$ ). (B) Representative photomicrographs of the micropore membranes of SDF-1 $\alpha$ at concentrations from 0.1 to $100 \mathrm{ng} / \mathrm{ml}$ (bars, $100 \mu \mathrm{m}$ ).

few cells migrated towards the unconditioned medium with or

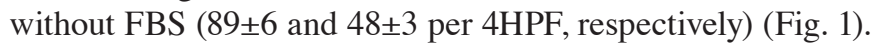
Every CM from glioma cell lines significantly stimulated the directional migration of mouse iPS cells compared to unconditioned medium with or without FBS $(\mathrm{p}<0.001)$.
The migration of mouse iPS cells towards increasing concentrations of specific growth factors, such as SCF, SDF-1 $\alpha$ VEGF and PDGF-BB (Fig. 2) was then assessed. Specifically, $0.1-100 \mathrm{ng} / \mathrm{ml}$ of specific growth factors were placed in the lower chambers. Migration was assayed after $24 \mathrm{~h}$ by counting 
A

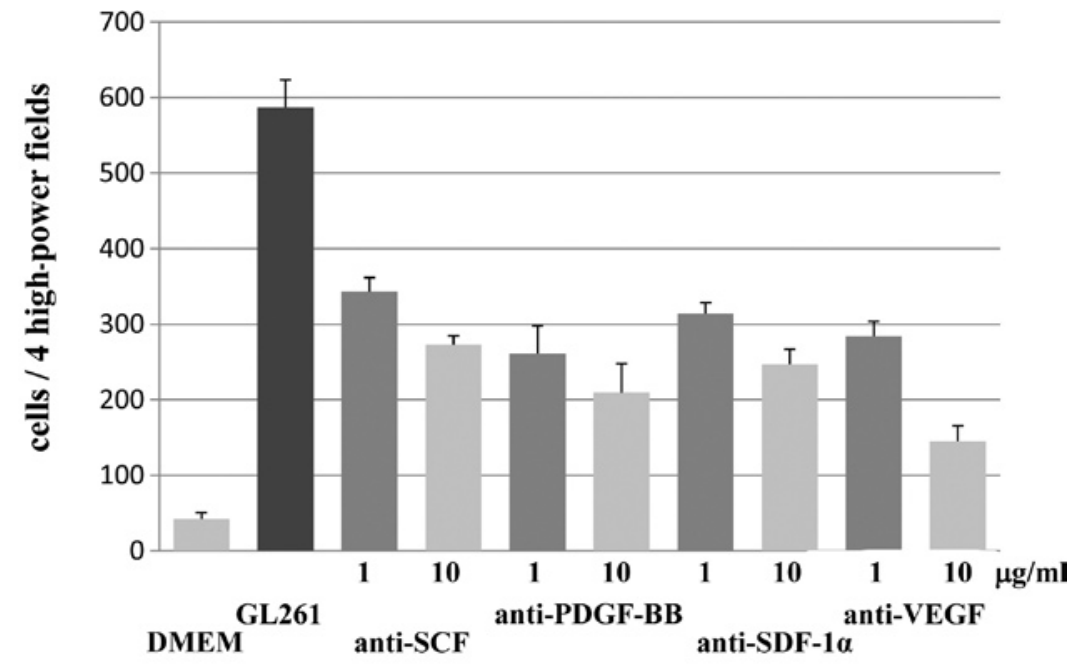

B
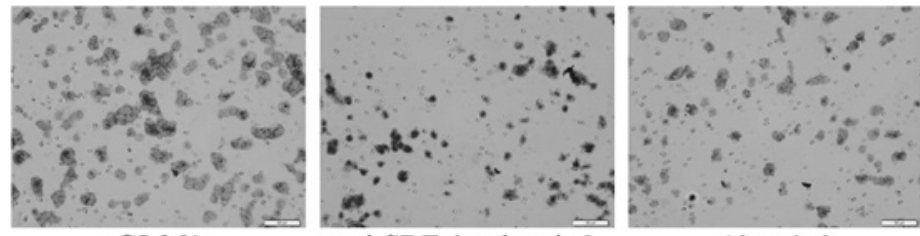

GL261

anti-SDF-1 $\alpha 1 \mu \mathrm{g} / \mathrm{ml}$

$10 \mu \mathrm{g} / \mathrm{ml}$

Figure 3. (A) Migration assays were performed using GL261-CM treated with the inhibitory monoclonal neutralizing antibodies of the growth factors at concentrations of 1 and $10 \mu \mathrm{g} / \mathrm{ml}$. Enhanced migrations of the mouse-induced pluripotent stem cells by GL261-CM mouse were significantly attenuated by the treatment with anti-stem cell factor, anti-platelet-derived growth factor BB, anti-stromal-derived factor-1 $\alpha$ and anti-vascular endothelial growth factor antibodies (triplicate, means $\pm \mathrm{SD},{ }^{*} \mathrm{p}<0.001$ ). (B) Representative photomicrographs of the micropore membranes of GL261-CM treated with $0,1 \mathrm{and} 10 \mu \mathrm{g} / \mathrm{ml}$ of the anti-SDF- $1 \alpha$ antibody (bars, $100 \mu \mathrm{m}$ ).

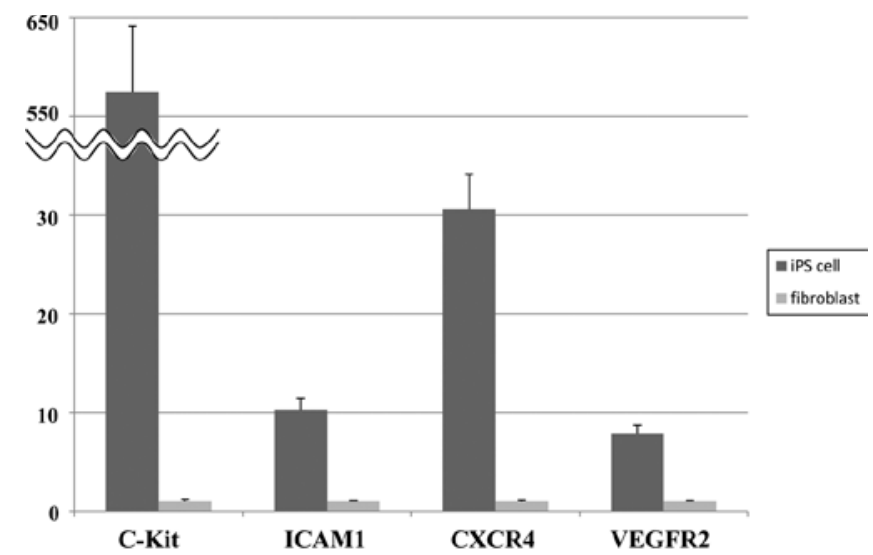

Figure 4. Expression of the receptors for four growth factors (c-Kit, ICAM-1, CXCR4 and VEGFR2) in the mouse-induced pluripotent stem cells and mouse fibroblasts was analyzed by reverse transcriptase-polymerase chain reaction (RT-PCR). The values were normalized to $\beta$-actin expression. The mRNA expression of the growth factor receptors was significantly up-regulated in the mouse iPS cells compared to the mouse fibroblast (means $\pm \mathrm{SD},{ }^{*} \mathrm{p}<0.001$ ).

the number of mouse iPS cells in 4HPF on the membrane. The migration of mouse iPS cells increased significantly with the stimulation of each specific growth factor (SCF, SDF-1 $\alpha$ VEGF and PDGF-BB) at concentrations of $0.1,1,10$ and $100 \mathrm{ng} / \mathrm{ml}$ compared to the unconditioned medium without FBS $(\mathrm{p}<0.001)$. Furthermore, the number of migrating mouse iPS cells increased dose-dependently with concentrations of each specific growth factor from 0.1 to $100 \mathrm{ng} / \mathrm{ml}$.
To investigate whether the increase in the migration of mouse iPS cells towards CM prepared from glioma cell lines was specifically attributable to the presence of specific growth factors, migration assays were performed using $\mathrm{CM}$ from the GL261 mouse glioma cell line treated with increasing concentrations of the inhibitory monoclonal anti-SCF, SDF-1 $\alpha$, VEGF and PDGF-BB antibodies that neutralized the activity of SCF, SDF-1 $\alpha$, VEGF and PDGF-BB, respectively. The high level of the migration of mouse iPS cells that resulted following exposure to native CM from the GL261 mouse glioma cell line was significantly attenuated by treatment with the inhibitory monoclonal anti-SCF, anti-SDF- $1 \alpha$, anti-VEGF and anti-PDGF-BB antibodies (Fig. 3). The application of the antibodies without any $\mathrm{CM}$ did not show any effect on mouse iPS cell migration (data not shown). The inhibition was dose-dependent, with $10 \mu \mathrm{g} / \mathrm{ml}$ of antibodies resulting in more effective inhibition of mouse iPS cell migration compared to $1 \mu \mathrm{g} / \mathrm{ml}$ of antibodies. Anti-SCF, anti-SDF- $1 \alpha$, anti-VEGF and anti-PDGF-BB antibodies $(10 \mu \mathrm{g} / \mathrm{ml})$ blocked the effects of $\mathrm{CM}$ by $46.5,42.1,24.6$ and $35.7 \%$, respectively. On the other hand, $1 \mu \mathrm{g} / \mathrm{ml}$ of anti-SCF, anti-SDF- $1 \alpha$, anti-VEGF and antiPDGF-BB antibodies blocked the effects of CM by 58.5, 53.5, 48.4 and $44.5 \%$, respectively. Furthermore, the combination of all the antibodies showed a stronger attenuating effect of mouse iPS cell migration, with $10 \mu \mathrm{g} / \mathrm{ml}$ blocked by $18.2 \%$ and $1 \mu \mathrm{g} / \mathrm{ml}$ by $32.2 \%$. Taken together, these results indicate that tumor-derived specific growth factors (SCF, SDF-1 $\alpha$ VEGF and PDGF-BB) promote the migration of mouse iPS cells towards gliomas in vitro. 
Expression of the receptors for growth factors. The expression of four different growth factor receptors, c-Kit, CXCR4, VEGFR2 and ICAM-1, was analyzed in mouse iPS cells using RT-PCR (Fig. 4). As a positive control, mouse fibroblasts were analyzed in parallel. All of the growth factor receptors were found to be expressed by the mouse iPS cells. When the values were normalized to $\beta$-actin expresssion, c-Kit, CXCR4, VEGFR2 and ICAM-1 mRNA expression in mouse iPS cells was significantly up-regulated compared to the mouse fibroblasts $(\mathrm{p}<0.001)$.

\section{Discussion}

Following the establishment of mouse iPS cells generated from mouse skin fibroblasts by the retroviral introduction of four transcription factors (Oct3/4, Sox 2, c-Myc and Klf4) (23), various cell transplantation studies were performed due to the high reproductive and pluripotent ability of iPS cells (26-29). For iPS cells to function appropriately, the migratory activity of iPS cells to the appropriate regions is crucial. Although numerous studies have shown the in vitro and in vivo tumortropic migratory ability of NSCs and MSCs to malignant gliomas $(6,7,9,11,12,15,30,31)$, studies of migratory activity of iPS cells have yet to be performed.

This study aimed to examine the migratory capacity of mouse iPS cells towards gliomas in order to evaluate the usefulness of iPS cells as vehicles for glioma gene therapies. The migration of mouse iPS cells was significantly stimulated by CM from six rodent and human glioma cell lines as well as four specific growth factors that are secreted by gliomas (SCF, PDGF-BB, SDF-1 $\alpha$ and VEGF) (19-22). Furthermore, the expression of the corresponding receptors (c-Kit, ICAM-1, CXCR4 and VEGFR2) was also significantly up-regulated in the mouse iPS cells. These findings indicated that soluble factors secreted by malignant glioma cells, including the four growth factors examined, were potent inducers of mouse iPS cell migration.

However, factors other than these four growth factors that stimulate the migration of mouse iPS cells may be produced by the glioma cells to various extents, depending on the cell line. The heterogeneity of growth factor production presumably expresses the in vivo differences in the biological behavior of malignant gliomas, including the proliferative and invasive natures associated with the expression profiles of cytokines, interleukins and growth factors, such as transforming growth factor- $\beta 1$ (TGF- $\beta 1$ ) (32-34) and matrix metalloproteinases (35). Other specific growth factors known to be expressed in malignant gliomas are fibroblast growth factor-1 (FGF-1), PDGF-AA, insulin-like growth factor-1 (IGF-1), scatter factor/ hepatocyte growth factor $(\mathrm{SF} / \mathrm{HGF})$ and TGF- $\alpha,-\beta 1$ and $-\beta 2$ $(36,37)$. A number of these factors already play a role in the stimulation of NSC migration (31).

The results of the present study showed that the four specific growth factors (SCF, PDGF-BB, SDF- $1 \alpha$ and VEGF) serve as attractants for mouse iPS cells. Subsequently, blocking experiments were performed by adding the inhibitory monoclonal antibodies for those factors in the CM from GL261 mouse glioma cells known to secrete numerous specific growth factors. Stimulated mouse iPS cell migration by GL261 CM was significantly inhibited by all the neutralizing antibodies examined, indicating that the presence of these specific growth factors was significantly responsible for the chemoattractant capacity of the CM.

Various types of stem cells are known to express the receptors for SCF, PDGF-BB, SDF-1 $\alpha$ and VEGF (c-Kit, ICAM-1,CXCR4 and VEGFR2, respectively) (38,39). These receptors were highly expressed in the mouse iPS cells. The presence of ligand/receptor combinations of the chemoattractive factors, such as SCF/c-Kit, PDGF-BB/ICAM-1, SDF-1 $\alpha$ / CXCR4 and VEGF/VEGFR2, allow malignant glioma and iPS cells to communicate with each other and, consequently, facilitate the migration of iPS cells to gliomas.

The present study showed, for the first time, that mouse iPS cells exerted marked tropism to glioma CM and at least four specific growth factors (SCF, PDGF-BB, SDF-1 $\alpha$ and VEGF). The tropism was blocked by the neutralizing antibodies for these growth factors. The majority of the malignant glioma cells are supposed to secrete numerous soluble factors that attract mouse iPS cells, although the amount is variable among the tumors. Additionally, mouse iPS cells recognize a broad spectrum of signals from malignant glioma cells as migration triggers. These observations suggest that iPS cells are likely to aid as therapeutic vehicles for the treatment of malignant gliomas if they are genetically modified to express therapeutic transgenes that encode oncolytic agents, apoptosisinducing factors, interleukins, factors that inhibit angiogenesis and the suicide genes.

We have investigated the use of NSCs and MSCs as therapeutic vehicles for a suicide gene therapy, HSVtk/GCV, and obtained encouraging results in pre-clinical models (14-18). However, the use of this strategy for patients is hampered by significant limitations, such as the isolation of clinically viable and legally utilizable sources and ethical problems (20). Similarly, iPS cells remain in pre-clinical phases and also experience ethical problems, including cell tumorigenesis $(40,41)$. If tumor formation of the iPS cells is adequately regulated and all of the variables affecting safety issues are rigorously evaluated, the clinical use of iPS cell-based therapies may become a useful tool in the field of regeneration therapy. The results of the present study strongly suggest that the use of iPS cells as therapeutic vehicles for the delivery of suicide genes is a novel strategy for the treatment of malignant gliomas. Additional studies are required to compare the migration characteristics of iPS cells to those of NSCs and MSCs, particularly under in vivo conditions.

\section{Acknowledgements}

This study was supported in part by the Japan Society for the Promotion of Science Young Investigators Grants (S.K.).

\section{References}

1. Michotte A, Neyns B, Chaskis C, Sadones J and In't Veld P: Neuropathological and molecular aspects of low-grade and highgrade gliomas. Acta Neurol Belg 104: 148-153, 2004.

2. Louis DN, Ohgaki H, Wiestler OD, et al: The 2007 WHO classification of tumours of the central nervous system. Acta Neuropathol 114: 97-109, 2007

3. Surawicz TS, Davis F, Freels S, Laws ER Jr and Menck HR: Brain tumor survival: results from the National Cancer Data Base. J Neurooncol 40: 151-160, 1998. 
4. DeAngelis LM: Brain tumors. N Engl J Med 344: 114-123, 2001.

5. Nakamizo A, Marini F, Amano T, et al: Human bone marrowderived mesenchymal stem cells in the treatment of gliomas. Cancer Res 65: 3307-3318, 2005.

6. Aboody KS, Brown A, Rainov NG, et al: Neural stem cells display extensive tropism for pathology in adult brain: evidence from intracranial gliomas. Proc Natl Acad Sci USA 97: 12846-12851, 2000

7. Benedetti S, Pirola B, Pollo B, et al: Gene therapy of experimental brain tumors using neural progenitor cells. Nat Med 6: $447-450,2000$

8. Ehtesham M, Kabos P, Gutierrez MA, et al: Induction of glioblastoma apoptosis using neural stem cell-mediated delivery of tumor necrosis factor-related apoptosis-inducing ligand. Cancer Res 62: 7170-7174, 2002.

9. Ehtesham M, Kabos P, Kabosova A, Neuman T, Black KL and Yu JS: The use of interleukin 12-secreting neural stem cells for the treatment of intracranial glioma. Cancer Res 62: 5657-5663, 2002.

10. Kim SK, Cargioli TG, Machluf M, et al: PEX-producing human neural stem cells inhibit tumor growth in a mouse glioma model. Clin Cancer Res 11: 5965-5970, 2005.

11. Kim SK, Kim SU, Park IH, et al: Human neural stem cells target experimental intracranial medulloblastoma and deliver a therapeutic gene leading to tumor regression. Clin Cancer Res 12: 5550-5556, 2006.

12. Lee DH, Ahn Y, Kim SU, et al: Targeting rat brainstem glioma using human neural stem cells and human mesenchymal stem cells. Clin Cancer Res 15: 4925-4934, 2009.

13. Sasportas LS, Kasmieh R, Wakimoto H, et al: Assessment of therapeutic efficacy and fate of engineered human mesenchyma stem cells for cancer therapy. Proc Natl Acad Sci USA 106: 4822-4827, 2009.

14. Amano S, Li S, Gu C, et al: Use of genetically engineered bone marrow-derived mesenchymal stem cells for glioma gene therapy. Int J Oncol 35: 1265-1270, 2009.

15. Li S, Gao Y, Tokuyama T, et al: Genetically engineered neural stem cells migrate and suppress glioma cell growth at distant intracranial sites. Cancer Lett 251: 220-227, 2007.

16. Li S, Tokuyama T, Yamamoto J, Koide M, Yokota N and Namba H: Potent bystander effect in suicide gene therapy using neural stem cells transduced with herpes simplex virus thymidine kinase gene. Oncology 69: 503-508, 2005.

17. Li S, Tokuyama T, Yamamoto J, Koide M, Yokota $\mathrm{N}$ and Namba H: Bystander effect-mediated gene therapy of gliomas using genetically engineered neural stem cells. Cancer Gene Ther 12: 600-607, 2005.

18. Namba H, Tagawa M, Iwadate Y, Kimura M, Sueyoshi K and Sakiyama S: Bystander effect-mediated therapy of experimental brain tumor by genetically engineered tumor cells. Hum Gene Ther 9: 5-11, 1998.

19. Schichor C, Birnbaum T, Etminan N, et al: Vascular endothelial growth factor A contributes to glioma-induced migration of human marrow stromal cells (hMSC). Exp Neurol 199: 301-310, 2006.

20. Ehtesham M, Yuan X, Kabos P, et al: Glioma tropic neural stem cells consist of astrocytic precursors and their migratory capacity is mediated by CXCR4. Neoplasia 6: 287-293, 2004

21. Serfozo P, Schlarman MS, Pierret C, Maria BL and Kirk MD: Selective migration of neuralized embryonic stem cells to stem cell factor and media conditioned by glioma cell lines. Cancer Cell Int 6: 1, 2006

22. Hata N, Shinojima N, Gumin J, et al: Platelet-derived growth factor BB mediates the tropism of human mesenchymal stem cells for malignant gliomas. Neurosurgery 66: 144-157, 2010
23. Okita K, Ichisaka T and Yamanaka S: Generation of germlinecompetent induced pluripotent stem cells. Nature 448: 313-317, 2007.

24. Takahashi K, Okita K, Nakagawa M and Yamanaka S: Induction of pluripotent stem cells from fibroblast cultures. Nat Protoc 2: 3081-3089, 2007.

25. Mohanam S, Sawaya R, McCutcheon I, Ali-Osman F, Boyd D and Rao JS: Modulation of in vitro invasion of human glioblastoma cells by urokinase-type plasminogen activator receptor antibody. Cancer Res 53: 4143-4147, 1993.

26. Amabile $G$ and Meissner A: Induced pluripotent stem cells: current progress and potential for regenerative medicine. Trends Mol Med 15: 59-68, 2009.

27. Koch P, Kokaia Z, Lindvall O and Brustle O: Emerging concepts in neural stem cell research: autologous repair and cell-based disease modelling. Lancet Neurol 8: 819-829, 2009.

28. Ronaghi M, Erceg S, Moreno-Manzano V and Stojkovic M: Challenges of stem cell therapy for spinal cord injury: human embryonic stem cells, endogenous neural stem cells, or induced pluripotent stem cells? Stem Cells 28: 93-99, 2010.

29. Yu J and Thomson JA: Pluripotent stem cell lines. Genes Dev 22: 1987-1997, 2008

30. Cheng P, Gao ZQ, Liu YH and Xue YX: Platelet-derived growth factor $\mathrm{BB}$ promotes the migration of bone marrow-derived mesenchymal stem cells towards C6 glioma and up-regulates the expression of intracellular adhesion molecule-1. Neurosci Lett 451: 52-56, 2009.

31. Heese O, Disko A, Zirkel D, Westphal M and Lamszus K: Neural stem cell migration toward gliomas in vitro. Neuro Oncol 7: 476-484, 2005

32. Brat DJ, Bellail AC and van Meir EG: The role of interleukin- 8 and its receptors in gliomagenesis and tumoral angiogenesis. Neuro Oncol 7: 122-133, 2005.

33. Mentlein R and Held-Feindt J: Pleiotrophin, an angiogenic and mitogenic growth factor, is expressed in human gliomas. J Neurochem 83: 747-753, 2002.

34. Teicher BA: Malignant cells, directors of the malignant process: role of transforming growth factor-beta. Cancer Metastasis Rev 20: 133-143, 2001

35. Nagashima G, Suzuki R, Asai $J$ and Fujimoto $T$ : Immunohistochemical analysis of reactive astrocytes around glioblastoma: an immunohistochemical study of postmortem glioblastoma cases. Clin Neurol Neurosurg 104: 125-131, 2002.

36. Dunn IF, Heese O and Black PM: Growth factors in glioma angiogenesis: FGFs, PDGF, EGF, and TGFs. J Neurooncol 50: $121-137,2000$.

37. Hamel W and Westphal M: Growth factors in gliomas revisited. Acta Neurochir 142: 113-138, 2000.

38. Das AV, James J, Zhao X, Rahnenfuhrer J and Ahmad I: Identification of c-Kit receptor as a regulator of adult neural stem cells in the mammalian eye: interactions with Notch signaling. Dev Biol 273: 87-105, 2004.

39. Tran PB, Ren D, Veldhouse TJ and Miller RJ: Chemokine receptors are expressed widely by embryonic and adult neural progenitor cells. J Neurosci Res 76: 20-34, 2004.

40. Baudino TA, McKay C, Pendeville-Samain H, et al: c-Myc is essential for vasculogenesis and angiogenesis during development and tumor progression. Genes Dev 16: 2530-2543, 2002.

41. Miura K, Okada Y, Aoi T, et al: Variation in the safety of induced pluripotent stem cell lines. Nat Biotechnol 27: 743-745, 2009. 